\title{
UM OLHAR ETNOARQUEOLÓGICO PARA A OCUPAC̄̃AOO GUARANI NO ESTADO DE SÃO PAULO
}

\author{
Robson Antonio Rodrigues \\ Doutorando, Universidade de São Paulo - Brasil \\ Marisa Coutinho Afonso \\ Universidade de São Paulo - Brasil
}

Resumo: Os processos de formação do registro arqueológico podem ser identificados através de pesquisas etnoarqueológicas. A Etnoarqueologia utiliza analogias etnográficas, principalmente a partir das observações de aspectos do comportamento de grupos humanos contemporâneos, visando estudar o material arqueológico e sua relação com esse comportamento. O Estado de São Paulo tem sido identificado como uma área de fronteiras entre grupos ceramistas pré-coloniais e os arqueólogos tentam compreender melhor a ocupação Guarani, especialmente no vale do rio Paranapanema, no sul do Estado. Comparações entre as informações etnográficas e os achados arqueológicos estão sendo feitas, como a identificação das casas-grandes Guarani às manchas de terra preta encontradas nos sítios arqueológicos e o conjunto destes núcleos de solo antropogênico às aldeias. A compreensão da ocupação Guarani nos períodos pré-coloniais pelos arqueólogos tem sido alterada pelos dados etnográficos e estudos que tratem das relações dos Guarani com outros grupos, como os Jê, estão sendo desenvolvidos.

Palavras-chave: arqueologia, etnoarqueologia, ocupação Guarani, sítio arqueológico.

Abstract: Formation processes of the archaeological record can be identified through ethnoarchaeological researches. Ethnoarchaeology uses etnographic analogies, mostly from observation of aspects of contemporaneous behavior, aiming to study the archaeological remains and their relation with this behavior. The State of São Paulo has been recognized as a frontier between different precolonial ceramic groups, and archaeologists try to better understand the Guarani occupation, specially at the Paranapanema valley, in the southern part of the state.Comparisons between etnographic informations and archaeological remains are being made, as the identification of the Guarani big houses to the black earth found at archaeological sites, and the set of these antropogenetic soils to the settlements. The understanding of precolonial Guarani occupation has been 
modified by archaeologists using etnographic data, while studies about the relations between Guarani and other groups, like Jê, are under way.

Keywords: archeological site, archaeology, ethnoarcheology, Guarani occupation.

As primeiras questões levantadas pelo arqueólogo ao encontrar um objeto arqueológico são: o que é isto? Para que foi usado?

A Arqueologia, ou melhor, os arqueólogos sempre interpretaram os achados arqueológicos tirando conclusões com base, principalmente, em suas observações feitas no presente, sobre as populações que já desapareceram e deixaram seus materiais espalhados pelo solo. Estes vestígios do passado, por sua vez, não consistem de comportamentos humanos, mas são resultados dos procedimentos e produtos desses comportamentos.

Uma observação comumente aceita entre diversos pesquisadores como historiadores, geólogos, paleontólogos, e também, arqueólogos, entre outros, coloca que o passado, embora nunca diretamente observável, é, contudo, conhecível (Gould; Watson, 1982).

Se pensarmos a partir dos resultados de pesquisas que procuram entender as populações atuais, como as etnológicas, perceberemos que seus pesquisadores não têm acesso a certos fatores do comportamento humano. Nesse sentido, esta situação pode ser separada "por meio de hipóteses que têm implicações para esses comportamentos" (Wobst, 1978, p. 303).

$\mathrm{Na}$ atualidade, constata-se um crescimento do interesse em descobrir questões mais amplas quanto à dinâmica e ao funcionamento da cultura, principalmente uma inter-relação entre a construção simbólica e a materialidade das sociedades, bem como a lógica interna que possibilita a sobrevivência de certos modos culturais (Hernando Gonzalo, 1995). Esse interesse é fruto de novas orientações que estão envolvendo a Arqueologia, principalmente a partir do debate proporcionado pelo pós-processualismo.

Novos problemas arqueológicos, de extrema complexidade, passam a ficar sem explicação, ou pouco explicados, quando tratados por um ou outro referencial teórico.

Seguindo essa linha de pensamento, F. Silva aponta para uma série de mudanças no contexto teórico-metodológico, principalmente a partir da Nova Arqueologia norte-americana. Para essa autora,

um dos procedimentos adotados foi a intensificação da pesquisa em contextos etnográficos a fim de observar e documentar as relações 
entre o comportamento humano e a matriz material-espacialambiental em que ele toma lugar e, a partir disso, desenvolver teorizações sobre os processos de formação do registro arqueológico. (Silva, F., 2000, p. 11).

Esse novo modo de pensar o registro arqueológico passa a se chamar Etnoarqueologia, que, em seu sentido mais amplo, pode ser entendido como uma abordagem que visa proporcionar os meios para que se possa interpretar a estática do registro arqueológico, tendo como referencial a dinâmica do contexto etnográfico.

Ou seja,

[...] a partir do estudo de sociedades contemporâneas, proporciona os meios para formular e testar hipóteses, modelos e teorizações que possibilitam responder questões de interesse arqueológico (Silva, F., 2000, p. 30).

Na história da pesquisa arqueológica, a utilização de dados etnográficos sempre foi uma constante. Porém, novos estudos têm estimulado os arqueólogos a repensar suas análises tipológicas e as classes de objetos, na formulação de novas interpretações. Instigados por diferentes correntes teóricas como o Estruturalismo, o Marxismo e a Antropologia interpretativa, a abordagem pós-processual passa a reorientar os estudos etnoarqueológicos. Concentrando sua ênfase nos estudos dos aspectos simbólicos da experiência humana, ressaltam o papel ativo e transformador da cultura material nas sociedades estudadas, o que dá um caráter de diversidade interpretativa dos temas e objetos de pesquisa, bem como de referen-ciais teóricos (Silva, F., 2000).

Nesse sentido, as novas pesquisas, ao incorporar os trabalhos etnoarqueológicos da Arqueologia processual, promovem uma crítica a sua abordagem empirista e reordenam a direção dos estudos, contemplando, agora, os sistemas simbólicos dos grupos pesquisados.

Entendido como o resultado do uso que a Arqueologia sempre fez dos dados etnográficos, a Etnoarqueologia embasa-se nesses estudos na busca de sugestões para a resolução dos problemas arqueológicos, principalmente quando se faz necessário o entendimento da dinâmica e, mesmo, do comportamento de populações pretéritas. 
Para Miller, "dados etnográficos orientados em termos de sítios podem ser úteis ao proporcionar possibilidades alternativas para a interpretação de artefatos e estruturas escavadas" (Miller, 1982 apud Gould, 1971, p. 297).

Os dados gerados com a informação coletada de sociedades recentes e sua cultura material podem ser aplicados como fonte de hipóteses que possibilitem inferir explicações da dinâmica social pretérita, "considerando a possibilidade de que existam semelhanças quanto às características organizativas das sociedades, seu nível tecnológico, seu entorno ambiental e à conjunção destes aspectos" (Fournier, 1994, p. 187).

Para proceder estudos entre o material arqueológico e sua relação com o comportamento humano, a Etnoarqueologia utiliza-se de analogias etnográficas ${ }^{1}$, principalmente a partir das observações de aspectos do comportamento de grupos humanos contemporâneos, para corroborar no entendimento de fatos e processos do passado (Monticelli, 1995; Oliveira, 1999).

Esses estudos, ao explicitarem as relações entre cultura material e comportamento, procuram fornecer pressupostos teóricos no processo de interpretação arqueológica, o que aumenta o potencial arqueológico, já que considera todas as informações observáveis do comportamento humano.

A Etnoarqueologia pode oferecer referenciais que corroboram para a construção de um marco geral na compreensão de uma determinada cultura. Pode assinalar que possíveis racionalidades deviam estar presentes no momento da formação de um determinado registro material, e, portanto, pensarmos em determinados comportamentos ideológicos, sociais, tecnológicos, como agentes desse registro (Hernando Gonzalo, 1995).

Por meio do referencial teórico em questão, é possível entender determinados aspectos do comportamento humano pretérito que, muitas vezes, são deixados de lado em algumas observações arqueológicas. Mesmo usada com cautela e em situações específicas, a analogia etnográfica permite alcançar um conhecimento satisfatório do passado estudado, principalmente quando aplicada às pesquisas em que se observa uma continuidade cultural geograficamente determinada, como é o caso das pesquisas realizadas no interior do Estado de São Paulo.

\footnotetext{
1 “A analogia etnográfica forma parte inevitável do raciocínio arqueológico. Não poderíamos imaginar um passado diferente de nosso presente se não fosse pela evidência de um presente também diferente; não teríamos atribuído funcionalidades e usos, e nem sequer poderíamos classificar determinados objetos a não ser pela analogia etnográfica. A atribuição de significados a objetos, estruturas, espaços, etc., sua identificação, não poderia realizar-se sem ela" (Hernando Gonzalo, 1995, p. 20).
}

Horizontes Antropológicos, Porto Alegre, ano 8, n. 18, p. 155-173, dezembro de 2002 
Mesmo sendo difícil encontrar estudos etnológicos que fundamentem diretamente as análises etnoarqueológicas, pode-se utilizar fontes publicadas, de arquivos, de resultados experimentais, etc. (Hernando Gonzalo, 1995). O que implica, de algum modo, uma relação entre dados das sociedades historicamente conhecidas e o conhecimento do passado arqueológico, integrando-se dados etno-históricos e etnográficos com os arqueológicos (Monticelli, 1995 apud Kramer, 1979).

Para Stiles (1977), a Etnoarqueologia é uma subdisciplina da Antropologia e é definida como englobando todos os aspectos teóricos e metodológicos dos dados comparativos etnográficos e arqueológicos incluindo o uso da analogia etnográfica e etnografia arqueológica. Segundo este autor, há cinco principais fontes para a obtenção de informações relevantes arqueologicamente: estudos etnográficos, publicações de viajantes, coleções de cultura material dos museus, estudos experimentais e estudos etnográficos explicitamente arqueológicos.

$\mathrm{Na}$ bibliografia etnológica o arqueólogo procura resgatar informações a respeito do modo de vida das populações estudadas, no que se refere, por exemplo, à produção e significação da sua cultura material, padrão de subsistência e assentamento, uso do espaço, deslocamentos territoriais e contatos com outras populações. (Silva, F., 2000, p. 42).

Nesse contexto, o conhecimento etnológico passa a ser um direcionador, um norte, que permite, ao arqueólogo, a busca de informações tanto específicas como gerais, para o estabelecimento de correlações entre o comportamento humano e os elementos materiais da cultura.

E, com a pesquisa etnoarqueológica, são fornecidas pistas importantes para interpretar e complementar análises arqueológicas, que não contam mais com os dados sobre a sociedade que elaborou, usou e descartou os objetos localizados nos sítios arqueológicos, constituindo-se, assim, em "um recurso fundamental para o entendimento dos processos de formação do registro arqueológico" (Silva, F., 2000, p. 228).

Wust (1992) sugeriu "uma intensificação de pesquisas que possam estabelecer continuidades e rupturas entre o registro arqueológico e etnológico por meio de um uso sistemático das fontes históricas primárias e da investigação etnoarqueológica", o que está sendo desenvolvido em várias regiões brasileiras. Recentemente, vários pesquisadores têm desenvolvido trabalhos etnoarqueológicos com diferentes grupos indígenas como Monticelli (1995), Oliveira (1999), Silva, F. (2000), Silva, S. B. (2001), Rodrigues (2001), entre outros. 


\section{Problemática ocupacional dos grupos ceramistas}

O entendimento da ocupação de áreas no Estado de São Paulo por grupos ceramistas pré-coloniais ainda é bastante incompleto e localizado, mesmo com as diversas pesquisas já realizadas e em curso.

Tal motivo é apontado por Robrahn-González (1999), em parte, pelo fato de se contar com grandes extensões territoriais praticamente desconhecidas e por outro lado, mesmo nas regiões em que têm sido realizados estudos prolongados, o número de sítios identificados varia de acordo com a própria natureza, objetivos e alcances das pesquisas desenvolvidas, além de apresentarem consideráveis variações que não foram ainda sistematicamente exploradas.

Para o Estado, estudos arqueológicos têm definido, até o momento, três grandes unidades classificatórias, definidas como tradições: a tradição Tupiguarani, a tradição Itararé e a tradição Aratu/Sapucaí.

A tradição Tupiguarani é considerada, a partir de uma cronologia de ocorrências, a que aglutina os grupos ceramistas mais antigos. Essa tradição é subdividida em Guarani e Tupinambá. Boa parte do território paulista é ocupada por vestígios arqueológicos deste grupo.

Estando relacionada com populações do tronco lingüístico Jê, mais especificamente os Kaingang, a tradição Itararé, mais concentrada no Estado, está presente na região Centro-Sul, com uma aglutinação de sítios no vale do Ribeira de Iguape e vale do Itararé, no alto Paranapanema.

Uma terceira tradição, Aratu/Sapucaí, foi identificada na década de 90 na bacia do rio Paraíba do Sul, no leste de São Paulo, e depois foram localizados sítios no extremo-norte do Estado, na bacia do Rio Grande.

A grande diversidade de contextos ambientais a que esses grupos ceramistas se associam, além da própria amplitude temporal e espacial de seus assentamentos leva a uma matriz cultural bem mais complexa. "[...] Longe de constituir uma unidade, ao contrário, fornecem importantes indícios de especificidades locais e regionais" (Robrahn-González, 1999, p. 4).

Mesmo não se originando no Estado, essas unidades de classificação arqueológicas estão sendo apontadas, por pesquisas em curso, como elementos centrais para identificar o território paulista, numa região que se caracteriza por limites fronteiriços entre diferentes populações ameríndias. Nesse sentido, o vale do Paranapanema é apontado como um referencial estratégico para se pensar essa questão. 
Duas são as principais tradições a ocuparem o vale: a tradição Tupiguarani (com suas subdivisões) e a tradição Itararé. Ao longo do Paranapanema e seus afluentes prevalece a tradição Tupiguarani, apontando para um domínio territorial deste grupo. A tradição Itararé concentra-se no alto Paranapanema, nas imediações do vale de um afluente homônimo (RobrahnGonzález, 1999/2000).

Por fim, parece haver, segundo Araújo (1995), um limite ecológico/ cultural bem delimitado entre tradição Itararé (grupo cultural Kaingang) e tradição Tupiguarani (principalmente o grupo Guarani). Tal limite se daria na altura da cidade de Itapeva. Ao norte da mesma, no domínio dos sedimentos da bacia do Paraná, o relevo torna-se mais suave, colinar e várias são as evidências arqueológicas ligadas às populações Tupi-Guarani, na forma de sítios arqueológicos e de urnas funerárias. Ao sul, cessam todas as manifestações desse grupo e tem-se a presença única de sítios cerâmicos ligados às populações Jê.

\section{Instalação e utilização de ambientes naturais pela populacão Guarani}

Abrangendo uma imensa área, o território ocupado pelos Guarani, no século XVI, situava-se entre o Chaco até o Atlântico, das capitanias do sul até o Rio da Prata, sendo hoje, no Brasil, constituído pelos Estados do Rio Grande do Sul, Santa Catarina, Paraná, São Paulo e Mato Grosso do Sul, além de partes de países vizinhos como a Argentina, Uruguai e Paraguai (Monteiro, 1992).

Esclarece ainda Monteiro (1992) que esse território não era ocupado de modo homogêneo ou exclusivo já que esse povo se encontrava principalmente nas florestas tropicais e subtropicais, ao longo do litoral e entre os principais rios do sistema Paraná-Paraguai-Uruguai.

Muitas vezes apresentados como inertes, dóceis serviçais dos missionários europeus ou ainda vítimas dos famigerados bandeirantes, os Guarani, longe dessa visão, "desenvolveram estratégias próprias que visavam não apenas a mera sobrevivência mas, também, a permanente recriação de sua identidade e de seu modo de ser, frente às condições progressivas adversas" (Monteiro, 1992, p. 475).

Com relação à demografia, Fausto (1992) argumenta que a despeito das incertezas do cálculo demográfico, as crônicas da época deixam claro 
que, por um lado, tratava-se de populações expressivas e, por outro, que o nível de depopulação durante o primeiro século da colonização foi brutal. As guerras, as expedições para captura de escravos e, principalmente, as epidemias e a fome dizimaram brutalmente as populações indígenas.

Os efeitos do contato e da conquista alteraram profundamente a constituição da organização desses povos. Dois fatores são apresentados por Monteiro (1992), podendo exemplificar essa situação: por um lado, o abrupto declínio populacional em função do fator epidemiológico e, por outro, o recuo estratégico dessas populações para áreas de acesso mais difícil.

Os contatos entre indígenas e europeus obrigaram os Guarani a alterarem partes consideráveis de sua cultura e organização social, principalmente por conta de grande depopulação. Esse fato afetou diretamente o modelo tradicional de sua organização, reduzindo-o estruturalmente, bem como diminuindo sua complexidade.

Mesmo apresentando um cenário diverso, faz-se necessário entender um pouco mais desse complexo sistema de organização social. Para Monteiro (1994), embora as primeiras fontes identifiquem, por meio das denominações étnicas, aquilo que se pode considerar como conjuntos tribais, na verdade a aldeia representa a principal unidade da organização social dos grupos Tupi.

As maiores aldeias eram compostas por um número variável de malocas dispostas em torno de um pátio central, ou mesmo ao longo do rio principal, possuíam uma população de quinhentos até dois ou três mil índios. Porém, em alguns casos, ocupavam as proximidades dos afluentes, com um número populacional reduzido. Segundo Prous (1992), todos os indígenas moravam na aglomeração central, a não ser durante breves períodos de pesca ou guerra, durante os quais a população podia se dividir.

A distância entre os diversos grupos locais não era uma constante, mas variava em função das condições ecológicas e políticas de cada região. Várias aldeias eram ligadas por laços de consangüinidade e aliança, mantendo relações pacíficas entre si, participando de rituais comuns, reunindo-se para expedições guerreiras de grande porte, auxiliando na defesa do território. Esse conjunto de grupos locais circunvizinhos não estava sujeito a uma autoridade comum, nem possuía fronteiras rígidas, pois estes grupos eram fruto de um processo histórico em andamento, no qual se definiam e redefiniam constantemente as alianças (Fausto, 1992). Estas constantes mutações decorrentes de circunstâncias históricas influíam no caráter e duração dos laços multicomunitários. 
Essas aldeias não constituíam povoados fixos e permanentes, pois, após alguns anos, os grupos tendiam a mudar-se para um novo local. Diversos motivos podiam contribuir para o deslocamento de uma aldeia: o desgaste do solo, a diminuição das reservas de caça, a atração de um líder carismático, uma disputa interna entre facções ou a morte de um chefe. Contudo, qualquer que fosse a razão, a repetida criação de novas unidades de povoamento constituía-se em um evento importante, envolvendo a reprodução das bases da organização social indígena (Monteiro, 1994).

Cada tribo conservava-se dentro dos limites de seu território. No entanto, as aldeias mudavam freqüentemente de lugar transferindo-se para locais vizinhos, muitas vezes a menos de um quilômetro do local anterior.

Para Noelli (1993),

Uma aldeia não poderia ocupar novas terras sem preparação prévia, pois os Tupi transportavam suas plantas, inserindo-as por todas as regiões em que se instalavam, bem como se apropriavam de novos vegetais que iam conhecendo. Não podiam mudar-se para um território muito distante das aldeias aliadas. A expansão não pode ter ocorrido por saltos; necessariamente se dava por uma anexação contínua e paulatina de áreas imediatamente adjacentes aos territórios já ocupados.

Soares (1997) comenta que a arquitetura Guarani ainda não foi explorada suficientemente como fonte, mesmo assim, podem-se estabelecer analogias onde se observa que as casas maiores são habitadas por maior número de pessoas e, conseqüentemente, com dimensões espaciais maiores.

Nesse aspecto, informa ainda Maestri (1994) que uma comunidade Tupi-Guarani de três ou quatro centenas de membros necessitava de um espaço econômico de subsistência e de coleta de matérias-primas de aproximadamente $45 \mathrm{~km}$. Em algumas regiões ricas em recursos naturais, apenas alguns quilômetros separavam uma aldeia da outra.

Um detalhe que marca a ocupação das populações Guarani se dá pela forma como essas utilizaram as condições ecológicas disponíveis.

Verifica-se que estes grupos nunca se interessaram em progredir nas regiões secas, como o cerrado; também não se adaptaram às terras frias, evitando as regiões acidentadas, ou muito altas. Em compensação, sempre são encontrados vestígios materiais destes povos, a certas distâncias dos rios 
navegáveis, em zonas da mata pluvial litorânea, tropical ou subtropical, nos grandes vales meridionais ou nas zonas do centro-sul, ou ainda nas matas ciliares (Prous, 1992).

A idéia de ocupação de ambientes específicos é sustentada também por Kern (1994), ao sugerir que se trata de um padrão de instalação das aldeias na paisagem, oriundo da região amazônica. Os Guarani buscam os vales quentes e úmidos próprios das florestas tropicais e subtropicais, subindo os vales dos rios que percorrem as encostas do planalto sul-brasileiro, até altitudes não superiores a 700 metros, enquanto predominam as condições de calor e umidade.

Os verões frescos e os invernos frios do planalto não atraíram os Guarani. O clima não era favorável ao plantio das espécies vegetais dos trópicos. Mais para o norte, os vales dos rios Iguaçu e Paranapanema eram quentes e úmidos e serviram de caminho para extensas penetrações que levaram os horticultores Guarani através do planalto, de oeste para leste (Kern, 1994, p. 106).

Por meio de pesquisas arqueológicas em áreas de ocorrência de vestígios materiais de ocupações antigas já estudadas, pode-se comprovar e, em muitos casos, esclarecer os dados obtidos por meio dos relatos de cronistas.

Essa exigência por parte dos Guarani atendia às suas necessidades constantes de terras férteis em virtude do tipo de cultivo utilizado. A busca do local para a instalação da aldeia, em clareiras no meio da floresta subtropical, além de uma visão estratégica, visava também ao abastecimento de água e à possibilidade da complementação da subsistência por meio da pesca, caça e várzeas férteis dos rios (Kern, 1994; Scatamacchia; Moscoso, 1989).

Neste sentido, a cultura Guarani se assentava em um complexo econômico baseado na caça, na pesca, na coleta e, sobretudo, numa agricultura de floresta ${ }^{2}$. Plantavam mandioca, que era utilizada em larga escala por toda população, principalmente, como farinha, que era consumida com peixe ou caça moqueada, na produção de bebidas alcoólicas (cauim) ou em forma de beiju; além de várias qualidades de milho, feijão, batata, cará, amendoim,

\footnotetext{
2 Sobre os aspectos alimentares dos Guarani, Francisco Noelli realizou um amplo levantamento em sua dissertação de mestrado intitulada "Sem Teko'a não há Teko - em busca de um modelo Etnoarqueológico da aldeia e da subsistência Guarani e sua aplicação a uma área de domínio no delta do rio Jacuí-RS".
} 
abóbora, banana, abacaxi, tabaco, algodão, pimenta entre outros. Também se serviam do sal que era produzido principalmente das cinzas ou do mar (Brochado, 1989; Maestri, 1994).

Existia uma distinção entre as roças de cada família, já que os principais tinham condição de obter ajuda de vários homens para trabalhar em suas plantações, num sistema de manejo agroflorestal ${ }^{3}$. Essas eram desmatadas coletivamente, mas em seguida trabalhadas por cada um; encontravam-se a duas ou três léguas da aldeia e o processo era a coivara. A produção de bens materiais realizava-se no contexto de uma divisão sexual e etária do trabalho. Os homens responsabilizavam-se pela caça e pelo preparo dos campos para as plantações; as mulheres pelas restantes atividades agrícolas e também as ceramistas. Com o deslocamento para outras áreas, as roças abandonadas eram reaproveitadas durante anos já que continuavam fornecendo produtos cultivados e atraindo caça (Maestri, 1994; Prous, 1992).

Sendo a organização social definida por Florestan Fernandes (1963) como "um conjunto de atividades, de ações e de relações sociais dos seres humanos em condições determinadas de existência social e de caráter adaptativos ou integrativo, ordenadas em uma configuração social de vida", a organização dos Guarani se dava por famílias extensas, compostas por várias famílias nucleares ${ }^{4}$ reunidas em torno de um principal (liderança política e/ou religiosa), cada uma ocupando uma grande casa comunal. (Brochado, 1989; Noelli, 1999/2000).

Esta era subordinada estreitamente ao sistema religioso tribal na visão de Fernandes (1963). Determinava, em grande parte, o tipo de comportamento dos indivíduos e as principais atividades e cerimônias coletivas. Sua influência exercia-se por meio de todas as estruturas sociais.

\footnotetext{
3 “O manejo era feito no interior do Teko'a, o território de domínio de cada assentamento, entrecortado por trilhas que interligavam as aldeias e estas às roças, áreas de coleta, pesqueiros, áreas de caça, etc. Uma vez que as aldeias formavam conjuntos unidos politicamente por meio de alianças regionais, além dos laços de parentesco, havia um sistema de trocas de mudas e sementes como ocorre entre vários povos com o mesmo tipo de sistema agroflorestal, garantindo a disseminação de espécies entre os teko'a". (Noelli, 1999/2000, p. 249).

4 "As famílias extensas compunham-se de um número variável de famílias nucleares, que poderia atingir 60 ou mais, residindo em uma única casa. As maiores aldeias podiam conter até 4 ou 5 famílias extensas, havendo relatos de assentamentos com 3000 habitantes, mas a média parece estar restrito a populações em torno de 600-300 pessoas. [...] A família nuclear seria composta em média por seis membros. Havia a possibilidade de existir até sete gerações convivendo em uma família extensa, o que pode aumentar a média do tamanho local da família nuclear" (Noelli, 1999/2002, p. 248).
}

Horizontes Antropológicos, Porto Alegre, ano 8, n. 18, p. 155-173, dezembro de 2002 
Nas aldeias, as principais lideranças exerciam um poder muito variável sobre o grupo local. Às vezes se confederavam debaixo de um único chefe sobre grandes áreas. "Longe do quadro homogêneo delimitado a partir das fontes coloniais, o cenário político era constituído por complexas configurações de aliança e conflito entre grupos locais, bem como entre grupos Guarani e outras sociedades indígenas" (Monteiro, 1992, p. 480).

O potencial bélico, os sistemas de alianças e de chefia estavam baseados no parentesco. O líder político, apesar de ocupar a função de chefia, devia conquistar seu prestígio e ser extremamente generoso.

Na opinião de Noelli (1999/2000), o principal fator agregador era o prestígio de um líder com capacidade de organizar grupos guerreiros ou de trabalho, com qualidades de bom orador, guerreiro, agricultor, caçador, articulista político e provedor de grandes festas. Nesse sentido, a poligamia aparece como um importante fator na rede de poder, contribuindo para ampliar o prestígio dos principais líderes.

Segundo Magni (1989), quanto maior o número de mulheres tivesse, mais presentes podia oferecer a comunidade, visto que eram as mulheres que os produziam, aumentando, assim seu status. Além disso, a poligamia permitia que o principal pudesse contar com uma extensa rede de parentesco e de alianças sociopolíticas, por conta da agregação de seus cunhados.

O mesmo papel do chefe - guardião das tradições - era compartilhado pelos xamãs que às vezes acumulavam, também, autoridade política. Os xamãs ocupavam entre os indígenas a posição de mediadores entre os espíritos e o resto do povo. Com efeito, como intermediários entre o sobrenatural e o cotidiano, os xamãs desempenhavam diversas funções essenciais, tais como o curandeirismo, a interpretação dos sonhos e a proteção da sociedade local contra ameaças externas, entre elas espíritos malévolos. Sua autoridade derivava principalmente do conhecimento esotérico que possuíam, resultado de longos anos de aprendizagem com xamãs experientes (Monteiro, 1994).

Para Monteiro (1992), a discussão em torno do conceito de chefia no contexto da organização Guarani, principalmente na perspectiva etno-histórica, está intrinsecamente articulada com a idéias de profetismo, já que se percebe que a religião se apresenta como um elemento unificador do povo Guarani. Todo o pensamento e prática religiosos dos índios estavam vinculados à idéia da Terra sem Mal (Yvy Marã Ey)

\footnotetext{
5 "Ivy Maraney, a Terra Sem Mal, na verdade, é o lugar do solo intacto, o espaço ainda não edificado, não transformado pela mão do homem de terra da natureza em local de cultura" (Brandão, 1990, p. 65).
}

Horizontes Antropológicos, Porto Alegre, ano 8, n. 18, p. 155-173, dezembro de 2002 
Discutindo com outros autores que estudaram este aspecto, Monteiro (1992, p. 481) salienta que os Guarani possuíam uma chefia forte, porém, na perspectiva de Pierre Clastres, a própria sociedade criava mecanismos para impedir a apropriação do poder pelos chefes. Esse mecanismo era permeado pela figura dos Karaí (profetas) que "contestavam a autoridade do chefe, evocando os mitos dos heróis-civilizadores e da Terra sem Mal por meio das belas palavras (discurso profético), dos cantos e danças e, por fim, das migrações", persuadindo "os índios a abandonarem suas aldeias em busca de um paraíso terrestre".

Na perspectiva de Hélène Clastres, que estudou os conflitos entre os tipos de autoridade Guarani, os discursos dos Karaí apontam para uma dinâmica indígena do movimento profético, pois o profetismo Guarani, inverso de um messianismo, provinha de conflitos e crises no interior da própria sociedade e não de fatores externos, como as crises desencadeadas pela conquista (Monteiro, 1992).

No contexto da sociedade Guarani, os Karaí, evocando a mitologia heróica e se pautando pelo conhecimento esotérico dos cantos sagrados, propiciavam ações tanto tradicionais quanto transformadoras. "Tradicional, pois buscava preservar dois elementos fundamentais para os Guarani: sua identidade e sua liberdade; e transformadora porque pregava a destruição da ordem existente justamente com vistas a alcançar o primeiro objetivo" (Monteiro, 1992, p. 482).

Ao proceder um conjunto de associações, "enquadrando os deslocamentos dentro do conceito da espacialidade que, junto com a tradição, formaria um dos grandes eixos do modo de ser Guarani", a partir da leitura de Meliá, feita por Monteiro, percebe-se que existe um importante elo entre a constante procura de terras novas para aldeias e roças e a migração profética, pois estes movimentos sugerem uma busca de um espaço geográfico e espiritual propício à recriação de um modo de vida próprio dos Guarani, "quer pela renovação do local de assentamento, quer pelo reencontro com uma terra mítica" (Monteiro, 1992, p. 482).

Em síntese, mesmo na atualidade, pode-se dizer que os Guarani são um povo que caminha. E nesse caminhar vão criando e recriando aspectos importantes de seu modo de ser. Resistindo às mudanças provocadas pela sociedade envolvente, por meio de significados religiosos fundamentados 
em seus mitos ${ }^{6}$, buscam inspiração num modo organizacional dos antigos heróis-civilizadores.

A palavra, valor divino (sagrado) na cultura Guarani, age como um elemento mediador entre os deuses e os homens. Por isso deve ser rezada, cantada e dançada. "As belas palavras são dádivas dos deuses, enviados pelo ser supremo para guiar a vida dos futuros homens" (Isquerdo, 1992, p. 9).

Nesse sentido, a manutenção étnica dos Guarani se volta para as condições de autonomia e destaque cultural, tendo como base um modo de ser milenar fundamentado pelo teko (Godoy, 1991).

É certo que essas idéias devem ser interpretadas com cautela, principalmente considerando-se as distâncias temporais presentes entre os diferentes momentos da história do povo Guarani, porém, para melhor compreender o universo aqui exposto, faz-se necessário o aprofundamento e a utilização de um enfoque regional, numa perspectiva interdisciplinar. Pois assim, essa perspectiva permitirá estabelecer, com maior precisão, o tamanho da população estudada, suas características sociais e culturais, bem como, na visão de Monteiro (1992), as transformações ocorridas através do tempo.

Atualmente os arqueólogos têm desenvolvido pesquisas à luz das informações etnográficas das sociedades Guarani. Morais (1999/2000) prefere chamar de Sistema Regional Guarani à tradição Guarani, desmembrada da tradição Tupiguarani por Brochado, e relaciona alguns achados arqueológicos às informações etnográficas, como as casas-grandes Guarani (tapy' iguassu) às manchas de terra-preta, núcleos de solo antropogênico nos sítios arqueológicos do vale do rio Paranapanema em São Paulo, e o conjunto destes núcleos à aldeia. Suas interpretações, baseadas no estudos de Schaden (1974) sobre aldeia Guarani, são baseadas em registros arqueológicos que demonstram algumas informações etnográficas, como a instalação dos grupos sempre no meio da mata.

Araujo (2001) sugere uma "fronteira" entre diferentes grupos portadores da cerâmica Tupiguarani, fronteira essa que separa os sítios do alto e do médio Paranapanema e pergunta se os sítios Tupiguarani do alto vale estariam relacionados a uma ocupação tupi.

\footnotetext{
6 “A subsistência da sociedade Guarani é o seu mundo religioso e é, justamente, a relação do homem com seus deuses que os mantêm como Eu coletivo, o que os reúne numa comunidade religiosa - a vida, a sobrevivência dessa comunidade está alicerçada em suas crenças, crenças essas que se constituem nas forças que mais solidificam a solidariedade grupal da tribo. Por isso, o Sagrado ocupa papel relevante na vida do Guarani, razão porque se manifesta em suas ações cotidianas." (Isquerdo, 1992, p. 5).
}

Horizontes Antropológicos, Porto Alegre, ano 8, n. 18, p. 155-173, dezembro de 2002 
Pesquisas desenvolvidas no âmbito do projeto "Arqueologia da Paisagem: cenas do Paranapanema Paulista (da pré-história ao ciclo do café)" apontam para o sítio Guarani mais antigo do Estado, o sítio Panema, localizado no município de Campina de Monte Alegre (Morais, 2000). Um fragmento cerâmico desse sítio apresenta $2030 \pm 200$ anos (datação por termoluminescência) enquanto um fragmento de osso humano localizado em uma urna cerâmica no mesmo sítio foi datato por radiocarbono em $290 \pm 40$ anos, sugerindo uma continuidade de ocupação do local da aldeia.

A bacia do rio Paranapanema representa um local importante para a pesquisa das ocupações Guarani no tempo e no espaço e também das relações entre estes grupos indígenas e outros como os Jê. Os estudos, em desenvolvimento, têm utilizado dos dados etnográficos para a interpretação dos registros arqueológicos.

\section{Considerações finais}

A discussão apresentada procurou percorrer um caminho ligado à formulação teórica no qual o objeto de análise pudesse ser evidenciado em seu contexto.

Utilizando-se de dados etnográficos, principalmente oriundos de pesquisas bibliográficas, considerados como norteadores dos estudos, foi possível observar aspectos da dinâmica cultural presentes na sociedade Guarani e aplicá-los à análise arqueológica, na busca de uma abordagem que privilegiasse os atores sociais da produção material, em seu contexto estudado.

Nessa abordagem, a busca de sugestões para a resolução de alguns problemas arqueológicos, principalmente no que diz respeito à continuidade cultural da região pesquisada, proporcionou um exercício de compreensão dos fenômenos sociais pretéritos.

Os últimos séculos antes da conquista européia (e também o próprio período de conquistas) se caracterizaram por um período de intensas transformações culturais, resultando no surgimento de uma série de variações regionais que passaram a constituir o padrão arqueológico regional, formando a grande densidade e diversidade de grupos etnograficamente conhecidos (Robrahn-González, 1996).

Sabendo que cada classe de materiais não tem obrigatoriamente um sentido único; colocado dentro de diferentes contextos, pode ter diferentes 
significações para a análise dos processos de trabalho e das formas de relações sociais que caracterizam as manifestações dos modos de vida e dos modos de produção que estão presentes na maneira como o grupo social consome o espaço no qual vive.

Muitas crônicas e narrativas dos viajantes anularam as particularidades dos povos indígenas, impondo-lhes novos atributos que se concretizaram na conquista do continente.

A imagem das populações indígenas foi sendo construída a partir da realidade americana e da cultura européia, segundo os interesses dos colonizadores, ao sabor das disputas pelo controle da nova terra. Estes invasores pouco se preocuparam em abarcar a complexidade cultural dos povos indígenas do além-mar. Observando o cotidiano indígena, selecionaram determinadas informações e relacionaram-nas ao universo cultural europeu.

O impacto da conquista européia sobre as populações nativas do continente americano foi imenso. É certo que milhares de pessoas morreram por causa do contato direto e indireto com os europeus e as doenças por eles trazidas.

De devoradores dos inimigos pelo ritual antropofágico, esses povos indígenas foram devorados e destruídos nas guerras de conquista dos colonizadores, em suas bandeiras e em suas missões.

Em menos de dois séculos, os numerosos Tupi-Guarani foram varridos do território brasileiro. Aqueles que não morreram pela violência, pelas epidemias ou pela fome fugiram para outras regiões.

De qualquer forma, porém, os Guarani conseguiram fazer memória de si. Mortos, ascenderam à imortalidade da lembrança. Hoje, mais de cinco séculos depois (e apesar de tudo), vários grupos insistem em continuar vivendo e afirmando, de modo dinâmico, seu modo de ser e sua diversidade cultural.

\section{Referências}

ARAUJO, A. G. de M. Levantamento arqueológico da área Alto Taquari, Estado de São Paulo, com ênfase na abordagem dos sítios líticos. Disseratação (Mestrado)-FFLCH/MAE/USP, São Paulo, 1995. 
ARAUJO, A. G. de M. Teoria e método em Arqueologia regional: um estudo de caso no alto Paranapanema, estado de São Paulo. Tese (Doutorado)-FFLCH/MAE/USP, São Paulo, 2001.

BRANDÃO, Carlos R. Os Guarani, índios do Sul: religião, resistência e adaptação. Estudos Avançados, São Paulo, ano 4, n. 10, p. 53-90, 1990.

BROCHADO, J. P. A expansão dos Tupi e a cerâmica da tradição policrômica amazônica. In: Dédalo, São Paulo, n. 27, p. 65-82, 1989.

FAUSTO, Carlos. Fragmentos de história e cultura tupinambá: da Etnologia como instrumento crítico de conhecimento etno-histórico. In: CUNHA, Manuela. C. (Org.). História dos índios do Brasil. São Paulo: SMC: Companhia das Letras, 1992. p. 381-396.

FERNANDES, F. Organização social dos Tupinambá. São Paulo: Difusão Européia do Livro, 1963.

FOURNIER, Patricia. La Etnoarqueologia y Arqueologia Experimental en el estudio de la alfareria Otomi de Valle del Mezquita, México. II Workshop de métodos arqueológicos e gerenciamento de bens culturais: cadernos de debates, Rio de Janeiro, IPHAN, n. 2, p. 185-201, 1994.

GODOY, Marilia G. G. Misticismo e etnicidade Guarani: radicalismo cultural no Estado de São Paulo. Terra indígena, São Paulo, ano 8, n. 60, p. 2238, 1991.

GOULD, Richard A.; WATSON, Patty Jo. A Dialogue on the meaning and use of analogy in Ethnoarchaeological reasoning. Journal of Anthopological Archaeology, n. 1, p. 355-381, 1982.

HERNANDO GONZALO, Almudena. La Etnoarqueología, hoy: una via eficaz de aproximaxión al pasado. Trabajos de Prehistoria, ano 52, n. 2, p. 15-30, 1995.

ISQUERDO, Aparecida N. A palavra sagrada na cultura Guarani: uma cultura do Ayvu-Rapita. Terra indígena, São Paulo, ano 9, n. 62, p. 4-12, 1992.

KERN, Arno A. Antecedentes indígenas. Porto Alegre: UFRGS, 1994.

MAESTRI, M. Os senhores do litoral: conquista portuguesa e agonia tupinambá no litoral brasileiro (Séc. XVI). Porto Alegre: UFRGS, 1994.

MAGNI, Claudia T. Guarani guerreiros. Estudos Ibero-americanos, Porto Alegre, n. 1, p. 229-241, 1989. 
MILLER JR., Tom O. Etnoarqueologia: implicações para o Brasil. Arquivo do Museu de História Natural, Rio de Janeiro, ano 1, n. 6/7, p. 293-309, 1982.

MONTEIRO, J. M. Os Guarani e a história do Brasil Meridional. In: CUNHA, M. C. (Org.), História dos índios do Brasil. São Paulo: SMC: Companhia das Letras, 1992. p. 475-498.

MONTEIRO, J. M. Negro da terra: índios e bandeirantes nas origens de São Paulo. São Paulo: Companhia das Letras, 1994.

MONTICELLI, Gislene. Vasilhas de cerâmica Guarani: resgate da memória entre os Mbyá. Dissertação (Mestrado)-PUCRS, Porto Alegre, 1995.

MORAIS, J. L. Arqueologia da região Sudeste. São Paulo, Revista da USP, n. 44, p. 194-217, 1999-2000.

MORAIS, J. L. Arqueologia da paisagem: cenas do Paranapanema paulista (da pré-história ao ciclo do café) [Relatório final]. FAPESP, 2000.

NOELLI, F. S. A ocupação humana na região Sul do Brasil: Arqueologia, debates e perspectivas 1872-2000. São Paulo, Revista da USP, n. 44, p. 218269, 1999-2000.

NOELLI, F. S. A. Sem Tekohá não há Tekó: em busca de um modelo etnoarqueológico da aldeia e da subsistência Guarani e sua aplicação a uma área de domínio no delta do rio Jacuí-RS. Dissertação (Mestrado)-PUCRS, Porto Alegre, 1993.

OLIVEIRA, L. M. A produção cerâmica como reafirmação de identidade étnica Maxacali: um estudo etnoarqueológico. Dissertação (Mestrado)MAE/USP, São Paulo, 1999.

PROUS, A. Arqueologia brasileira. Brasília: UnB, 1992.

ROBRAHN-GONZÁLEZ, E. M. Arqueologia em perspectiva: 150 anos de prática e reflexão no estudo de nosso passado. São Paulo, Revista da USP, ano 1, n. 44, p. 10-31, 1999/2000.

ROBRAHN-GONZÁLEZ, E. M. Os grupos ceramistas pré-coloniais do Centro-Oeste brasileiro. Revista do Museu de Arqueologia e Etnologia, São Paulo, n. 6, p. 83-121, 1996.

ROBRAHN-GONZÁLEZ, E. M. São Paulo, terra de fronteiras: a ocupação de grupos ceramistas pré-coloniais. São Paulo: MAE, 1999. Mimeografado. 
RODRIGUES, R. A. Cenários da ocupação Guarani na calha do alto Paraná: um estudo etnoarqueológico. Dissertação (Mestrado)-FFLCH/ USP, São Paulo, 2001.

SCATAMACCHIA, M. C. M.; MOSCOSO, F. Análise do padrão de estabelecimento Tupi-Guarani: fontes etno-históricas e arqueológicas. Revista de Antropologia, São Paulo, n. 30/31/32, p. 37-53, 1989.

SCHADEN, E. Aspectos fundamentais da cultura Guarani. São Paulo: EPU: Edusp, 1974.

SILVA, Fabíola A. As tecnologias e seus significados: um estudo da cerâmica dos Asuriní do Xingu e da cestaria dos Kayapó-Xikrin sob uma perspectiva etnoarqueológica. Tese (Doutorado)-FFLCH/USP, São Paulo, 2000.

SILVA, S. B. Etnoarqueologia dos grafismos “Kaingang”: um modelo para a compreensão das sociedades Proto-Jê meridionais. Tese (Doutorado)FFLCH/USP, São Paulo, 2001.

SOARES, André L. R. Guarani: organização social e arqueologia. Porto Alegre: EDIPUCRS, 1997. (Coleção Arqueologia, n. 4).

STILES, Daniel. Ethnoarchaeology: a discussion of methods and applications. Man, n. 12, p. 87-103, 1977.

WOBST, H. M. The Archaeo-ethnology of hunter-gatherers or the tyranny of the ethnografic record in archaeology. American Antiquity, ano 43, n. 2, p. 303-309, 1978.

WUST, Irmhild. Contribuições arqueológicas, etnoarqueológicas e etno-históricas para o estudo dos grupos tribais do Brasil Central: o caso Bororo. Revista do Museu de Arqueologia e Etnologia, n. 2, p. 13-26, 1992. 